\title{
Translating accurately or sounding natural?
}

The interpreters' challenges due to semantic typology and the interpreting process $^{1}$

\author{
Alberto Hijazo-Gascón \\ University of East Anglia
}

\begin{abstract}
Police interview interpreting is a complex task, as interpreters make difficult choices under pressure and time constraints. The main dilemma of the interpreter is whether to remain faithful to the original text, with the risk of rendering non-idiomatic translations, or to give preference to more idiomatic versions that may entail an addition or an omission from the original text. This article presents an analysis of Spanish-English bilingual police interviews in California. The analysis is based on the discrepancies found between an interpreter present in the interrogation and a control interpreter. This is an original methodology that can be used for future research in this and other contexts. The results show different types of inaccuracies in the interpretation, which can be attributed to contextual pressures and overall challenges of interpreting and to challenges related to typological differences between the two languages involved.
\end{abstract}

Keywords: interpreting, police interviews, typology, register, Spanish-English interpreting

\section{Introduction}

Interpreting in a police interview is a complex task that involves a number of risks of miscommunicating or mistranslating some information. The inaccuracies that can be found in interpreters' speech can be due to typological contrasts between the pair of languages involved or to some of the characteristics of the interpreting task itself, such as simplification and a tendency to focus on the content of the message rather than on its form. In the present paper, two suspects' interviews are analysed in order to provide a classification of different types of inaccuracies in these interpretations, based on the discrepancies between the versions of the original interpreter and the control interpreter.

These inaccuracies are not easy to avoid. When faced with a typological contrast, the interpreter needs to choose between a more natural and a more literal translation. In both cases, the outcomes involve potential changes to the original text, such as the addition or omission of information in the first case, or the addition of connotations in the latter. In other words, as noted by Russell (2002:117) "the interpreter is caught

\footnotetext{
1 This research is part of the TACIT Project (Translation and Communication in Training). I would like to thank Luna Filipović for allowing me to use the data she collected in California and for introducing me to the fascinating field of forensic linguistics. I am grateful to the Defence Attorney's Office in the State of California (USA) as well as to the police interpreters who shared these data for research purposes. Special thanks also to Chris Skedgel for his help with the preparation of this paper for publication. This research was supported by grants FFI2013-45553-C3-1-P and FFI2017-82460-P from the Spanish Ministry of Economy and Competitiveness.
} 
between the extreme of translating for 'skopos' or purpose/aim envisaged (Vermeer 1998:4) and the legal requirement for a faithful rendering of the original". At the same time, interpreters tend to focus on the transmission of the content of the message and pay less attention to its form, as they normally lack time for the translation of detailed nuances. However, in sensitive contexts - as in the case of suspects' interrogations- the loss of these details can have a negative impact on the police investigation.

This research is innovative and original because it combines "previous approaches to interpreting in forensic contexts and involves novel real-life data. It also provides a classification and an analysis that can be used for further research in other professional contexts and concerning other language pairs. It is also relevant as it shows awareness of the complexity of the interpreters' role and highlights the benefits of having a control interpreter and bilingual transcripts, at least in sensitive cases. The outcomes of this contribution can be used for further purposes such as training interpreters and police officers, so that they can be aware of the challenges that typological differences between languages, in addition to the interpreting process itself, pose for these professionals.

\section{Forensic linguistics and interpreting}

Interpreter-mediated communication has been one of the areas under study in forensic linguistics. The seminal work by Berk-Seligson $(1990,2009)$ on the role of the interpreter in court shows how the attention tends to be shifted from the witness or subject to the interpreter in these scenarios and how the interpreter's intervention can alter the trial process. As Russell (2002) points out, the role of the interpreter is key in legal contexts, because the arrest and the interview of the suspect take place before the trial and the outcome of the interview may indeed determine whether or not there will be a trial. The police interview is therefore the first opportunity for a suspect to present his or her explanation of events. In the case of a non-native speaker of an official language, the intervention of the interpreter is crucial to communicate a suspect's account of the facts. Russell (2002) also argues that the dynamics of the interpreted interview are very different from those of the monolingual interview. The oppositional dyad is transformed into a triadic mixture of opposition, cooperation and shifting alignments (Russell 2002:116). This additional difficulty in interpreter-aided interviews should be taken into account by police officers.

In order to have a better understanding of the interpreting process, two important variables should be considered, namely interpreting skills and language contrasts - two areas that pose challenges for the interpreters. In the following sections, the focus will be, first, on how general interpreting skills can affect the interpreting outputs in terms of simplification of the original text and changes of register. Second, the focus will be on language contrasts that make an exact translation difficult and which may result in changes in the semantic and pragmatic elements of the interpreter's version.

\subsection{Interpreting skills}

There are different modes of interpreting, with two being the most common: simultaneous -without a stop in the delivery of the source text and the production of the source text- and consecutive -with the delivery of the source text in chunks (Alexieva 1997:156). Hale (2007:22) claims that there are three factors involved in the conversion process from one language to another: knowledge of the target language (grammar, 
pragmatics, register), interpreting skills, and the theoretical approach that governs the reasons behind the choices. In the case of interpreting skills, the author includes notetaking, mastery of the different modes of interpreting (consecutive, simultaneous, sight translation), situational management (knowing when and how to interrupt, take turns, etc.), ability to make complex choices under pressure and the ability to concentrate and make use of long- and short-term memory.

The main problem in interpreting is that perfect interpretation is unattainable (Davidson 2000:180). Differences in linguistic form need to be interpreted in short amounts of time, which inevitably leads to differences in meaning. Even semantically similar utterances can vary greatly in the social evaluation of each language. According to Davidson (2000), time constraints force interpreters to edit and delete information. As explained by Biagini, Davitti and Sandrelli (2017), the interpreting practice can be very complex these days and new factors can play a role in the nature of the interpreting process, e.g. interpreting in more than two languages, having a larger audience, or remote interpreting (a modality of interpreting using videoconferencing).

The most common mode of interpreting in police interviews is liaison interpreting, which is a subtype of consecutive interpreting (Alexieva 1997). This is used in face-toface interactions, with a limited number of people being interpreted at the same time. This type of interpreting involves important challenges for the interpreter, for example the need to use notes and memory in order to keep and convey as much information as possible. Russell (2002) notes that there might be some difficulties in this modality when the participants 'chunk' the text arbitrarily, and the interpreter cannot interpret properly unless some crucial syntactic or context information is present in the chunk. In addition to this, in some cases there are difficulties in turn-taking, such as overlapping talk.

These difficulties lead interpreters to make choices, resulting in different outcomes in the interpreted text. Krouglov (1999) identifies some of these changes, such as the alteration or preservation of speech styles, the deletion or addition of information, and modifications due to politeness. Colloquialisms, jargon and social variation tend to be omitted or neutralised in the interpreter's speech. All these features of the interpreted version of the account of the facts may affect the outcomes of police interviews. The use of hedges, such as sort of, I guess, it seems, etc. is another common feature of interpreted speech that has been pointed out in the literature. Berk-Seligson (1990) notes that witnesses using hedges give the impression of being less convincing, less truthful, less competent, less intelligent and less trustworthy. These elements are at times modified, added or omitted by interpreters who are focused on conveying the main message of who did what to whom. This modification of hedges can entail the loss of potential relevant information and can affect the degree of certainty expressed increased or diminished- in the translated version.

According to Jacobsen (2002), most of the additions found in her court interpreting data are caused by the interpreter focusing on the transmission of the pragmatic meaning rather than on semantic content. These additions have different levels of impact on communication. They range from emphasising and down-toning additions, with significant impact, to explicating or elaboration additions (e.g. explicating nonverbal information or using an additional synonym) with minimal impact. The context also plays an important role in the quantity of additions and expansions used in interpreting. Braun (2017) compares data from face-to-face interpreting and remote interpreting, i.e. a modality of interpreting using videoconference, with a virtual space for the interaction. She finds that the additions and expansions are significantly more frequent in remote interpreting. 
In sum, changes between the source and target text in these areas are frequent in interpreting. As Krouglov (1999) notes, interpreters often alter the meaning of the utterances they interpret. They tend to change colloquialisms and hedges, and render the texts, using a more neutral register. They can also add particles or polite forms that may lead to an inaccurate perception of speakers by investigators. Stylistic features also tend to be lost in the translation. However, as Hale (2007:74) points out, interpreters should be faithful to the significance of content and manner of the suspect's answers. If they omit what they consider irrelevant, if they change register or make answers less hesitant (as is more frequent with untrained interpreters), they are in control of the verbal evidence by deciding what should and should not be included and recorded.

\subsection{Applied Language Typology}

Typology is the branch of linguistics that focuses on the comparison of languages and their classification according to different criteria, regardless of a language's origins and linguistic family affiliation. Different scholars have proposed several classifications of languages depending on different language levels: phonetics, syntax, semantics, etc. (Song 2010). The cross-linguistic differences studied in typology can have an impact on different language-driven activities, such as child language acquisition (Berman and Slobin 1994), second language acquisition (see Cadierno 2017 for an overview) and translation (Slobin 1996b).

Filipović (2007, 2011a, 2011b, 2016, 2017a, 2017b) has extensively applied typological insights to forensic linguistic contexts and legal translation. She defines Applied Language Typology (ALT) as "the study of the effects of typological contrasts that impact successful communication, learning, and professional practice" (Filipović 2017b: 399). One of the typologies used in within applied typological research is the semantic typology proposed by Talmy (1991, 2000). Talmy (1991, 2000) defines motion as change of location and a motion event contains four compulsory components: (i) Figure, the entity moving; (ii) Motion, the movement itself; (iii) Path, involving the directionality and the deixis of the movement; and (iv) Ground, the location where the motion event takes place.

Talmy's (1991) typology classifies languages depending on the most frequent way to encode the component of Path. If languages tend to encode this element outside the main verb of the event, in a so-called satellite like out, these are satellite-framed languages. This is the case of English, other Germanic languages, Slavonic languages, etc. When languages tend to encode Path in the main verb, they are classified as verbframed languages. This is the case of Spanish, which tends to use verbs like subir 'ascend', bajar 'descend', entrar 'enter', etc. as the main verb of the event.

There are also two optional components, or co-events, Manner and Cause of motion, which encode how the Figure moves or what causes the Figure to move. An English example is showed in (1), with Manner and Motion encoded in the verb and Path in the satellite:

$\begin{array}{ll}\text { She ran } & \text { out of the police station } \\ \text { Figure Motion } & \text { Path Ground } \\ \text { Manner } & \end{array}$

It is necessary only to give information about Path in order to express a motion event (e.g. 'He entered the building'). However, the habitual/typical lexicalisation pattern in English involves the use of manner verbs, as seen in example (1). In Spanish, it is not a 
matter of choice because the use of manner verbs is restricted to situations that do not involve crossing a physical boundary (e.g. 'Corrió en el parque' = 'He ran in the park'). Manner verbs cannot be combined with expressions that involve crossing a boundary in Spanish and this is why Path verbs are used and manner can be given in a gerund ('He ran into the park' $=$ 'Entró el el parque corriendo') ${ }^{2}$. Since gerunds are not obligatory, they can often be omitted in both original texts in Spanish and also in translation from English; thus information about the manner of motion can be lost in translation.

Research on this typology has shown that our narratives tend to be different, depending on whether our language is verb-framed or satellite-framed. Slobin (1991; 1996a; 1996b; 1997) has shown how speakers of satellite-framed languages tend to describe events with more dynamism, using more Manner information and more Path elements. For example, He dashed across the street. The fact that Path is encoded outside the verb, allows these speakers to encode Manner information easily in the main verb and therefore they do it more frequently. In fact, satellite-framed languages tend to have an extensive Manner verbs lexicon, involving first tier (semantically simpler) Manner verbs such as run, fly, jump, and second tier (semantically more complex) Manner verbs such as trudge, dash, creep (Slobin 1997). In contrast, speakers of verbframed languages tend to use more static descriptions. For example, Había una calle y la cruzó 'There was a street and he crossed it'. They encode Manner less frequently, since they need to add an extra element. For instance, an adverb like rápidamente 'quickly', a gerund like corriendo 'running', or a prepositional phrase like de prisa 'in a hurry'. Therefore, they only add Manner when it is particularly relevant. They also have a less grained vocabulary of Manner verbs, mainly consisting of first tier Manner verbs like saltar 'jump', correr 'run' and nadar 'swim'. Finally, they do not tend to include explicit information about the trajectories of the movement, as the direction is encoded in the verb and the trajectory can be inferred.

The challenges these differences have for translators and interpreters are clear. In a real-life example, an actress in a role-play with two detectives, as part of a suspect interview training course for police officers ${ }^{3}$, was playing the suspect role in the stabbing of her ex-husband at her house. During the interrogation by the two detectives, she was asked to explain in detail the moment in which the man was injured with the knife. The actress told them that her ex-husband was shouting at her while she was chopping cheese in the kitchen, and that at some point: I turned and he walked into the knife. This sentence encodes a heavy load of information in a very short space. The speaker marks the lack of intentionality by assigning the husband the agency of the action. Both the endpoint of the movement ('into the knife') and the manner of motion ('walked') are explicitly mentioned.

Interpreting this sentence is very challenging for an interpreter into a verbframed language. It would probably take several sentences to provide a translation that fully renders the original meaning in English. Due to time pressure, the most likely scenario is that some semantic information from the source text is left out in the translation: either Manner of motion, walk, or the end state of the motion event, i.e. the piercing act, or the intentionality of the action. In order to illustrate the point of how difficult a sentence like this would be for an interpreter, I asked three qualified

\footnotetext{
2 This semantic restriction was first noted by Aske (1989) and named boundary-crossing constraint by Slobin and Hoiting (1994).

3 I would like to thank the course leader of the suspect interview course at a UK Constabulary for allowing me to be present in some of their sessions and to use this material for research purposes. I am also thankful to the course co-leader and the participants in the course.
} 
interpreters how they would render this sentence into Spanish. Their answers were the following:

Le clavé el cuchillo accidentalmente

him stick.1SG.PST the knife accidentally

'I stuck him the knife accidentally'

$\begin{array}{llllllll}\text { Se } & \text { abalanzó } & \text { sobre } & \text { el } & \text { cuchillo } & y & \text { se } & \text { clavó } \\ \text { refl } & \text { leap.3SG.PST } & \text { over } & \text { the } & \text { knife } & \text { and } & \text { REFL } & \text { stick.3SG.PST } \\ \text { el } & \text { cuchillo } & & & & & & \\ \text { the } & \text { knife } & & & & & & \end{array}$

'He leapt on the knife and he stuck the knife on himself'

Se acercó de más hacia el cuchillo
refl approach.3SG.PST of more towards the knife
'He approached too much to the knife'

In (2) the interpreter changes the perspective: the agent of the stabbing action is the suspect, who is holding the knife, although the lack of intentionality of the action is highlighted. In (3) the man's agency is kept, but the Manner of motion information is changed, and its force dynamics ${ }^{4}$ increased (abalanzarse 'leap on' vs. walk). The interpreter in (4) leaves out the information about the end state, i.e. that the person was stabbed. This information is possibly implicit in de más 'too much' but it is not as explicit as in the original statement.

Manner of motion is therefore one of the main typological differences that are changed in translation (see Filipović 2007, 2017a, 2017b, Ibarretxe-Antuñano and Filipović 2013). However, this is not the only semantic component that has been studied from this research perspective. For example, intentionality is a key semantic component in caused motion (Ibarretxe-Antuñano 2012), and Spanish shows different degrees of encoding this intentionality, as it is the case in constructions like se me cayó 'it happened to me that it fell' vs. lo tiré 'I threw it' and lo dejé caer 'I let it fall'. Each of these constructions expresses a different degree of intentionality; however, when translated into English, they all fall under the label of drop (Filipović 2007, this issue). ${ }^{5}$ It has been also noted how these differences in the translation can have an effect on witnesses' testimonies (Filipović 2011; 2013) and impressions made on mock juries (Rojo and Cifuentes-Férez 2017), who tend to judge texts with more Manner of motion as being more violent (see also Filipović and Ibarretxe-Antunano 2013 on the role of dynamicity and people's judgements).

\section{Methodology}

The data under analysis in this paper are transcripts from California (USA). Unlike British transcripts, American transcripts are bilingual in English and Spanish, which allows for a clear revision of the transcript when needed. Moreover, a control interpreter

\footnotetext{
${ }^{4}$ Force dynamics relates to how two entities interact with regard to force (Talmy 1988). A translation with a strengthened force dynamics can lead the listeners or readers to understand the motion event as more violent than the original narrative (Filipović and Ibarretxe-Antuñano 2013).

${ }^{5}$ Modal verbs, such as may, might, could, etc. are likewise a semantic category with great variation across languages (Filipović 2016). For an overview with more examples of how typology can be applied to forensic contexts see Filipović (2017a; 2017b) and Filipović and Hijazo-Gascón (2018).
} 
(henceforth CI) transcribes and revises the interpreting of the first interpreter (I). The results presented in section 4 are part of the analysis of two bilingual Spanish-English transcripts of police interviews in California (containing over 57,300 words). The analysis will focus on the cases in which there is a discrepancy between both interpreters, which shows the benefits of the extra checking made by the CI.

I would like to emphasise that this approach focuses on the interpreting difficulties that are due to general interpreting skills challenges (not on professional competence of each individual interpreter) and to the typological contrasts between languages. Under no circumstances should this analysis be taken as criticising the interpreters' performance, and the discrepancies should not be understood as showing a lack of professionalism. One of the main purposes of the present paper is to raise awareness of the complexity of interpreting among specialists (interpreters and researchers in linguistics) and non-specialists (police officers, suspects, the general audience, etc.). Hopefully, the data analysis presented here make it clear that this was the aim to achieve.

\section{Results: Discrepancies}

As indicated above, in order to analyse the data, I identified the cases in which the control interpreter (CI) gives a different version from the first, original interpreter (I) and I assess both versions in relation to the original text. The overall research results are presented in Table 1. The analysis showed 15 different types of discrepancies between the two interpreters, with different frequencies in the number of occurrences. The percentages are calculated by taking into account the total number of discrepancies. As can be seen in Table 1, the most frequent types of discrepancies have to do with agentivity (17\%), loss of information (14\%) and loss of intensity in meaning $(8.5 \%)$. The majority of the discrepancies are due to typological contrasts, such as agentivity, manner of motion, modal verbs, deixis, etc. Other discrepancies are related to general interpreting skills, such as the use of euphemisms or grammar errors; these will be also included in the analysis. In the following subsections, the different types will be explained and illustrated with examples from the corpus, following the order of their frequency in the data (see also Wilson and Walsh, this volume, on the differences between police officers' and interpreters' perceptions about inaccuracy in interpreting).

\begin{tabular}{|l|l|l|}
\hline Type of discrepancy & Occurrences & Percentage \\
\hline Agentivity & 12 & $17 \%$ \\
\hline Loss of information & 10 & $14 \%$ \\
\hline Loss of intensity & 6 & $8.4 \%$ \\
\hline Manner of motion & 5 & $7 \%$ \\
\hline Modal verbs & 5 & $7 \%$ \\
\hline Euphemisms & 5 & $7 \%$ \\
\hline Grammar errors & 5 & $7 \%$ \\
\hline Addition of intensity & 5 & $7 \%$ \\
\hline Emotions & 4 & $5.8 \%$ \\
\hline Diminutives & 3 & $4.3 \%$ \\
\hline Hyperonyms & 2 & $2.8 \%$ \\
\hline Changes of information & 2 & $2.8 \%$ \\
\hline Deixis & 1 & $1.4 \%$ \\
\hline Mitigators & 1 & $1.4 \%$ \\
\hline
\end{tabular}

Table 1: Types of discrepancies between two interpreters, number of occurrences and percentages 


\subsection{Agentivity}

The category of agentivity comprises cases in which there are changes of meaning in relation to intentionality and cases related to different degrees in the expression of the agent of the action. In the first group, the examples found are similar to those explained above in relation to the contrast between drop and the corresponding expressions in Spanish, depending on the degree of intentionality. An illustrative example is given in (5):
S: $\quad Y$ dos veces que se me cayó en la grada
and two times that REFL to.me fell.3SG.PST in the stairs
I: $\quad$ that she fell on the stairs
CI: $\quad$ and two times when I dropped her on the steps

There is not an exact equivalent to the Spanish se-construction in English. As explained above, a potential equivalent, with clearly unintentional meaning, would be 'It happened to me that she fell on the stairs', but it is a very unnatural phrasing in English. The interpreter translation with fall leaves out the involvement of the speaker that is present in the Spanish text. The control interpreter uses drop in her new version, which in this case places the agentivity in the suspect and leaves the intentionality of the action ambiguous. This construction is arguably the most challenging one for English-Spanish interpreters and neither interpreter achieves adequate rendering of it.

Another problematic aspect related to agentivity is the translation of different degrees of involvement by the agent. An example is (6):
P: $\quad$ Did that go over the fence or did that get into the garbage can?
I: $\quad$ ¿Y eso lo tiró al otro lado de la fensa o lo puso en la basura?
"And did you throw this to the other side of the fence or it put in the rubbish?'
CI: And did you throw that over the fensa $a^{6}$ or did you put it in the rubbish?

In this case the thematic role of agent is shifted by both interpreters from an object to the person being interviewed. A literal translation into Spanish is not possible, as it is too unnatural to use verbs equivalent to go or get with inanimate objects in such a context. The indirect way of asking the question had to be abandoned in the Spanish translation and replaced with a much more direct phrasing of the question.

\subsection{Information loss}

There is a number of cases in which the interpreter simplifies the sentence and as a consequence, there is some loss of information. This can be due to different reasons, e.g. speed of the speech, or a heavy information load to be memorised. In some cases, the information lost can be relevant to the investigation, and some details might even be crucial for the identification of a suspect or for a clear account of the facts. Example (7) shows a loss of potentially relevant information:

$$
\mathrm{S}: \quad \text { Me } \quad \text { fui }
$$

al baño a lavarme

las manos

\footnotetext{
${ }^{6}$ Fensa is the Spanglish for 'fence'.
} 

REFL go.1SG.PST to.the bathroom to wash the hands
I: $\quad$ He went to wash his hands.
CI: $\quad$ I went to the bathroom to wash my hands.

The goal of motion, the bathroom, is not given in the first interpreter's translation and information about the location of the suspect or sequence of locations can bear relevance to the piecing of the suspect's narrative. ${ }^{7}$ The CI renders the relevant information.

\subsection{Loss of intensity}

The translations that fall under this category also involve simplification. However, unlike in the previous category, the main idea of the message is still transferred to the target language, albeit conveying a lower degree of intensity. For example, in (8) the idea of sickness is present in translation by the interpreter, but in a weaker manner:

$\begin{array}{lll}\text { S: } & \text { Como que se estaba } & \begin{array}{l}\text { desmayando } \\ \text { faint.GER }\end{array} \\ \text { I: like that REFL be.3SG.PST } & \text { She was kind of dizzy } & \\ \text { CI: like she was fainting } & \end{array}$

Similarly, whereas the translation by the interpreter in (9) does not specify the amount of blood, the original text does specify a great quantity of blood on the suspect's hands, which could be relevant for the police investigation.

$\begin{array}{lllll}\text { S: } & \begin{array}{l}\text { Cuando } \\ \text { when } \\ \text { sangre }\end{array} & \text { miré, look.1SG.PST, be.3PL.PST the hands full of } \\ \text { blood } & & \\ \text { I: } & \text {...and she was bleeding } \\ \text { CI: } & \text {...my hands were covered in blood }\end{array}$

In both these cases, the control interpreter $(\mathrm{CI})$ provides a more adequate rendering.

\subsection{Manner of motion}

As explained in section 2.3, Manner of motion is not a compulsory component of motion events (Talmy 1991, 2000); and in general, translation from English into Spanish involves the simplification of Manner of motion and, conversely, translation from Spanish into English involves the addition of Manner details in line with the preferred English pattern of using manner verbs (Slobin 1996b). As also mentioned in the previous literature, Manner of motion issues in interpreting are likewise present in the current data; see example (10):

$\begin{array}{llll}\text { (10) } & \text { S: } & \text { Subi } & \text { para arriba } \\ & & \text { ascend.1SG.PST } & \text { for upstairs } \\ & \text { I: } & \text { I ran upsta... I walked upstairs }\end{array}$

\footnotetext{
${ }^{7}$ Note that the use of third person by the interpreter is inadequate. Interpreters must use first person, just as the original speaker does. Otherwise, serious problems in identifying referents within a narrative could ensue.
} 


\section{CI: $\quad$ I went upstairs}

It is interesting to note how the interpreter corrects herself when realising that she is adding Manner to the original message. In the Spanish sentence, there is no mention of the speed of the movement, as only the direction is encoded. The control interpreter offers a more neutral translation and more closely related to the original. In this particular case, running upstairs (to wash his hands) could indicate that the suspect was in a rush to cover up his crime, which perhaps he was not, based on the original statement. In fact, the account by this suspect taken holistically reveals that things were happening in slow motion after the crime was committed, as if in a daze, not knowing what to do (which he also said explicitly at one point in his narrative). Another example of addition of Manner of motion, in this case caused motion, is present in (11):

$$
\begin{array}{llll}
\text { S: } & \text {..porque la llevaba de aquí } \\
& \text {..because her take.3SG.PST from here } \\
\mathrm{I}: & \text {...because when I was dragging her } & \\
\mathrm{CI}: & \text {...because I was holding her }
\end{array}
$$

In this case the first interpreter is adding Manner in relation to how the movement is done, which can imply connotations regarding the weight of the victim or the physical weakness of the suspect that are not present in the original text. The control interpreter does not add this meaning.

\subsection{Modal verbs}

Modal verbs are one of the areas of stark contrast between English and Spanish. English presents a wide variety of modal verbs, showing different degrees of probability, e.g can/could, will/would, may/might, etc., whereas Spanish tends to express modality with the verb poder, or with longer expressions similar to the English it is possible/probable that. This poses a challenge for interpreters, especially when they interpret from Spanish into English, since in order to choose the correct English modal verb, they have to assess the degree of certainty of the utterance that is not marked in Spanish.

In our dataset, some problems with the translations of the verbs querer and poder were found. The verb querer is generally translated as want but in some cases the control interpreter uses mean, as in (12):

$\begin{array}{lllll}\text { S: } & \text { Yo no quería } & \text { hacer esto } \\ & \text { I not want.3SG.PST do } & \text { this } \\ \text { I: } & \text { I did not want to do it } & & \\ \text { CI: } & \text { I did not mean to do it } & \end{array}$

Both translations are correct and correspond to the meanings of querer. However, in English there is a different connotation with the use of each of them. If the speaker says I did not mean it, the connotation is that this person did not have the intention to do it. In the case of I did not want to do it, the implication is that the person did not have any alternative. The interpreter needs to decide between these two because both interpretations fall under the meanings of querer. During one of the interviews, the interpreter translated querer as want, probably because it is the most frequent translation. However, the control interpreter feels the need to change this, maybe because this translation makes more sense within the context. 
There are some cases in which the problematic verb is poder, as in (13):

\begin{tabular}{|c|c|c|c|}
\hline S: & $\begin{array}{l}\text { porque } \\
\text { because }\end{array}$ & $\begin{array}{l}\text { podía } \\
\text { can.3SG.PST }\end{array}$ & $\begin{array}{ll}\text { llegar } & m i \\
\text { arrive } & m y\end{array}$ \\
\hline & my uncle & It get there & \\
\hline
\end{tabular}

The verb poder is usually translated as can or could, but in fact its meaning also covers the meanings of might and may which lack an equivalent verb in Spanish. The interpreter needs to choose and infer which translation is more appropriate; in this case the control interpreter opts for the more neutral verb.

This example is particularly interesting because the control interpreter is introducing a different temporal reference: might get there refers to the future (it is not sure if the uncle got there), whilst could have arrived entails a past possibility, i.e. that the arrival might have already happened. The Spanish original podía llegar is closer to might get. In fact, the suspect is explaining why he did not finish cleaning the crime scene. He stopped cleaning the stairs because he went upstairs to wash himself, as he was nervous that his uncle would arrive later. This change of information might affect how the speaker expectation is reflected in its narrative. It can also give rise to misunderstandings regarding the location of the suspect and his uncle at the moment of speaking, which could be relevant for police officers' investigation.

\subsection{Euphemisms}

There are a few cases in which the discrepancy between the interpreters is due to the use of a euphemism by the suspect that is rendered in a more direct manner by the interpreter present in the interview. The problem of these interpreting outcomes without the euphemisms is that they can create a different perception of the suspect, as less polite, less educated or too direct. An example would be when the suspect says hicimos lo que íbamos a hacer, which means 'we did what we were going to do' and which the CI translates as such. This euphemism covering sex is made explicit in the interpreter's translation as they had sex. It is not clear why the interpreter decided to be more explicit and avoid the euphemism. This could be due to different reasons such as simplification of information; in any case, it may have consequences for the impression that the police officer may get from the suspect. In other cases, the suspect says después hicimos el amor, which is translated as they have sex by the I and, more appropriately, as then we made love by the $\mathrm{CI}^{8}$. In other occasions the translation of the police officer speech is changed, as in Did she approach you or did you approach her? translated by the interpreter as ¿tú le preguntaste a ella que querías hacer sexo o ella te buscó?, which means 'did you ask her that you wanted to have sex or she looked for you?', and which may interfere with the police officer's aims of establishing rapport with the interviewee.

\subsection{Grammar errors}

This category includes grammatical errors made by the first interpreter, such as lack of agreement: It don't matter, instead of It didn't matter. In other cases, the mistakes have to do with conjugation, such as in verbal past tense (for example, he didn't thought

\footnotetext{
${ }^{8}$ See López Morales (2005) to know more about taboo and euphemisms in relation to social groups in Spanish-speaking countries.
} 
instead of he didn't think). These errors add connotations of marginalisation or lack of education about the person who is being interpreted. In the case of a witness, these connotations could inspire less trust in the speaker. It is important to bear in mind that the same connotations would not be inferred from the original messages in Spanish.

On the other hand, if the speaker was making these mistakes and the interpreter was correcting them in translation then we would have perceived the speaker as better educated (as Berk-Seligson (1990) noticed in the courtroom context). These grammar errors seem to be due to pressure stemming from interpreting task per se that is having an effect here rather than interpreter's lack of awareness.

\subsection{Addition of intensity}

Addition of intensity, the opposite of the situation in 4.3, is also found in the data, with the first interpreter adding intensity to the original expression by means of modifiers. For example, at one point, Me puse más nervioso is translated as extra nervous instead of more nervous. The use of repetition can also involve a change of register, with a more informal construction in English: "I am not leaving, I am not leaving" than in the original Spanish where "I am not leaving" is said only once (as correctly rendered by the $\mathrm{CI})$.

S: Me dijo: "Yo no me voy", entonces ella agachó a querer agarrar la cerveza y fue cuando le di yo

I: She say "I am not leaving, I am not leaving", and she tried to get the beer and that is when he hit her

CI: $\quad$ She told me "I am not leaving", so then she bent down to try to grab the beer and that is when I hit her

\subsection{Addition of information}

There are also some additions that are based on extra explanations for the interlocutor, i.e. the police officer. For example, at some point the interpreter clarifies: He is a bit confused; in other cases, the information added consists of details about places and objects. For example, ahí se me cayó 'I dropped her there' is translated adding a specified location: she fell on the concrete. Interpreters should not add this information, as they are supposed to be neutral and translate only the information given by the speakers, as the CI does.

\subsection{Emotions}

One of the interesting features highlighted by this analysis is the treatment of the suspect's emotions. This is the type of information that interpreters tend to omit in our data. Statements like: Me quedé asustado 'I was frightened' or porque me sentía mal 'because I felt bad' may seem superfluous to the interpreter, who needs to focus on the main part of the message, while in effect they involve connotations of the kind we saw above and they tended to be omitted by the interpreter (and rendered by the CI).

Interestingly, some of these cases also affect the translation of the police questions: ¿No estabas preocupado? 'Weren't you worried?' turns into ¿No crees? 'Don't you think?'. Berk-Seligson (2011) reports cases like these in which the interpreter, by not translating certain (portions of) sentences interferes with the attempt of the police 
officer to build a rapport with the suspect. A lack of information about the emotions of the suspect (and the police officer) might have an impact on their rapport and influence the way the interview is conducted. Building rapport between the interviewer and the person being interviewed is crucial in police interviews, and it is part of police training and practice (see Pounds this volume); likewise, investigating the feelings of the suspects facilitates rapport and helps to gain a better understanding of their motives and state of mind. A patterned omission of the information related to feelings of the suspects or witnesses can give the police officer an impression of coldness or distance. Similarly, when the police officer's emotions are not conveyed in the interpreted answers, there might be a failure to build a rapport with the suspect or the witness, which then may lead to the interviewed person appearing less responsive or cooperative.

\subsection{Other discrepancies}

In this final section, other discrepancies found are presented. Their frequency is low in the analysed transcripts, but further research could find more examples, as these discrepancies represent challenging areas for the interpreter.

First, diminutives are a linguistic device that is frequently used in Spanish. The primary meaning of diminutive suffixes involves a decreasing size of the referent, e.g. mesita (mesa + -ita) 'little table'. However, diminutives are frequently used as a pragmatic device to show affection (Alonso 1935) or as markers of positive politeness, to show involvement and solidarity with the interlocutor (Félix-Brasdefer 2006). English does not have any similar resources to convey this familiarity or rapport with the interlocutor; therefore, the translation will inevitably have to forego these connotative meanings. For example, the translator cannot but ignore the familiarity or irony of calladito (*'super-silent') and simply use quiet.

It is interesting to note that on one occasion the interpreter adds a diminutive to the question of the police officer, as shown in (15):

P: $\quad$ Okay, so she is dizzy, you're questioning what you did... what do you do next with her?

I: Bueno, él, ella estaba, este, mareada y tú well, he, she be.3SG.PST, this, dizzy and you te estabas preguntando qué hicistes ya qué refl be.2SG.PST wonder.GER what do.2SG.PST still what pasó despuesito? happen.3SG.PST after.DIM?

CI: $\quad$... what happened right after that?

Even though the use of diminutives with adverbs is more frequent in Mexican Spanish than in other varieties of the language, such use involves a change of register in the interpretation ${ }^{9}$. The use of a diminutive in Spanish could be interpreted as an unconscious attempt to establish rapport between the interlocutors through the

\footnotetext{
${ }^{9}$ Despuesito is not included as such in the dictionary of the Real Academia Española, not even under the lemma of después. It is found, though, in the Oxford Dictionary of Spanish as colloquially used in Guatemala, Mexico, Puerto Rico and Ecuador. A search in the CREA (Corpus of Reference for Current Spanish) shows only one occurrence for despuesito in a written text (the reproduction of an oral dialogue in direct style in a Colombian newspaper). Therefore, it clearly seems to belong to oral and informal speech.
} 
interpreter. The two essential dimensions of rapport are empathy and face, and diminutives are often considered as positive face linguistic devices, i.e. linguistic elements that are used to show closeness, affection and involvement (Curcó 1998).

In other cases, the problems identified are related to the use of more general or more specific terms in one of the two languages. Hyperonyms in the original can be spelled out in the translation, for example when the suspect says that they were consumiendo drogas 'consuming drugs' and the interpreter states that they did coke and they did crack. The interpreter is specifying the type of drugs consumed, thanks to information presented earlier in the conversation. This is an inference by the interpreter and does not reflect the exact words the suspect is using, again something that interpreters are trained not to do. Another related case was found in which the interpreter felt the need to over-specify the referent of a deictic expression. Deictic elements are those whose meaning is completed in accordance with context (Huang 2007): here, now, this, those, etc. In this case, the speaker uses allá 'over there', which the interpreter specifies as 'to the end of the hallway'. Going back to the original text, the control interpreter translates it as over there.

In other cases, the situation is the opposite. The suspect's discourse is more specific than the translation, for example when explaining he was using a manguera 'hose', which the interpreter translates as washing with water. In this case the lack of specificity of the answer triggers more questions from the police officers. The suspect can be confused by the officers' insistence (he has already explained what instrument he was using), and the officers can get the impression that the suspect is not cooperative enough. Another case was found, in which the interpreter simplifies the utterance and does not use the 'mitigator' used by the speaker ('mitigation' implies softening or modulating a speech act). When the suspect says Sí, yo creo que sí se miraba tomada ella 'Yes, I think she looked drunk', the interpreter omits I think in the translation. Needless to say, the lack of mitigators can have an impact on the impression the police officer has of the suspect, when nuances in the claims of the suspect, with clear legal implications, are omitted. However, this is the only case in both transcripts (see de Pablos-Ortega for more details on mitigation in this context).

\section{Discussion and conclusions}

The present paper presents an analysis of two interpreter-assisted police interviews, checked and transcribed by a control interpreter. Although the data set is limited, the analysis of the two interviews is thorough enough to shed some light on how the interpreting skills and typological differences impact on interpreting in legal contexts. The focus on grammatical, lexical and pragmatic features of both the original and the translation presents a coherent and comprehensive illustration of the issues that must be resolved during the interpreting process. And we add the cognitive effort that interpreting requires (Gile 1997) and the high sensitivity of the legal context, we can become aware of the challenges that police interview situations present for all participants.

The contrasts between the versions of the two interpreters are varied and they enabled us to detect different types of discrepancies. Some of them are due to typological contrasts between the pair of languages involved in the interpreting process (such as intentionality, manner of motion, modal verbs, deixis, etc.). In these cases, there is little the interpreter can do, since there is not a direct equivalent in the target language and therefore the conundrum will be whether to provide a more natural 
translation, with addition or omission of information, or to render a more literal translation, with the risk of sounding unnatural or adding connotations that could lead to potentially wrong inferences. Our analysis shows the frequency of the various types of inaccuracies due to typological contrasts, as found in previous studies using ALT (Filipović 2007; Filipović and Ibarretxe-Antuñano 2013; Filipović and Hijazo-Gascón 2018).

There are also some other cases of discrepancies are not due to typological contrasts per se, but to the nature of the interpreting process (loss or addition of information, loss or addition of intensity, euphemisms, grammatical errors, hyperonyms vs. specific terms and so on). Davidson (2000:400) observes that interpreters in medical settings "do in fact convey much of what is said, but they also interpret selectively, and appear to do so in a patterned (non-random) fashion". These results can be extrapolated to the police interview context analysed here. A number of these selections are arguably due to the fact that the interpreter focuses on the content of the message rather than on its form. This leads to oversimplifications and inaccuracies, probably owing to time pressure or to the main message being prioritised over other aspects present in the original message - aspects related to modality, rapport with the interlocutor and other pragmatic effects. These features are nevertheless important, as shown in previous research (Berk Seligson 1990) since they can affect the ways in which the speaker is perceived and the related judgment about the speaker by the listeners (e.g. jury members).

Our results complement findings in the previous literature focusing on interpreting in legal contexts, in particular with regard to the contrasts between Spanish and English in the United States (Berk-Seligson 1983; 1990; Filipović 2007, 2011, 2017a). They shed light on the specific types of inaccuracies committed, or overlooked, by the interpreters and the potential causes of these problematic communicative outcomes, either due to language-typological contrasts or to the interpreters' focus on conveying the main message rather than on respecting its form. Future research using more transcripts is needed to confirm the trends presented above. Work in other contexts and with other language pairs would also be relevant when it comes to pinpointing issues of general interpreting skills as well as problems of typological contrasts that are specific to the language pairs in question.

The role of control interpreters becomes crucial. They can check the accuracy of the first interpreter translation without being under the time pressure of the interpreting situation. Their presence also relieves some of the pressure on the interpreter who does the in situ interpreting. It is understandable that the costs of having a control interpreter are high and that it may not be possible to have one for every interview; even so, it should be considered mandatory in some cases, e.g. of serious crime. Similarly, the use of bilingual transcripts can help to clarify misunderstandings, while also easing the quality control processes that may follow the interrogation (e.g. based on police notes or testimony in court).

The present study may also have an impact on professional practices of interpreters and police officers, as it raises awareness of a number of meanings and interpretations that can be created or lost. Interpreters with a better awareness of the typological contrasts and other phenomena, such as modality in statements or intentionality specifications in event descriptions, can reflect on their own practice and note potential changes of information showing up in their translations. Police officers can be made more aware of the numerous respects in which interviews with interpreters differ from interviews without interpreters and become more adjusted to the complexities of the communicative situation, which is our daily reality in multilingual 
societies of today. Finally, this paper offered an insight into what kind of knowledge, skills and professional standards are required in this contexts in order to achieve access to justice for the people whose have to speak through an interpreter.

\section{References}

Alexieva, Bistra. 1997. "A Typology of Interpreter-Mediated Events". The Translator 3(2): 153-174.

Alonso, Amado. 1964 [1935]. "Noción, emoción, acción y fantasía en los diminutivos". In Estudios Lingüísticos. Temas españoles, 195-229. Madrid: Gredos.

Aske, Jon. 1989. "Path predicates in English and Spanish: A closer look". Proceedings of the Fifteenth Annual Meeting of the Berkeley Linguistics Society, 15, 1-14.

Berk-Seligson, Susan. 1983. "Sources of Variation in Spanish Verb Construction Usage: The Active, the Dative and the Reflexive Passive". Journal of Pragmatics 7: 145-168.

Berk-Seligson, Susan. 1990. The Bilingual Courtroom: Court Interpreters in the Judicial Process. Chicago: University of Chicago Press.

Berk-Seligson, Susan. 2009. Coerced Confessions: The Discourse of Bilingual Police Interrogations. Berlin: Walter de Gruyter.

Berk-Seligson, Susan. 2011. "Negotiation and Communicative Accommodation in Bilingual Police Interrogations: A critical Interactional Sociolinguistic Perspective". International Journal of the Sociology of Language 207: 29-58.

Berman, Ruth, and Dan I. Slobin (eds.). 1994. Relating Events in Narrative: A Crosslinguistic Developmental Study. Hillsdale: Lawrence Erlbaum

Biagini, Marta, Elena Davitti, and Annalisa Sandrelli. 2017. "Participation in Interpreter-mediated Interaction: Shifting along a Multidimensional Continuum". Journal of Pragmatics 107: 87-90

Braun, Sabine. 2017. "What a Micro-analytical Investigation of Additions and Expansions in Remote Interpreting Can Tell us About Interpreters' Participation in a Shared Virtual Space". Journal of Pragmatics 107: 165-177.

Cadierno, Teresa. 2017. "Thinking for Speaking about Motion in a Second Language. Looking Back and Forward". In Motion and Space across Languages. Theory and Applications, ed. by Iraide Ibarretxe-Antuñano, 279-300. Amsterdam: John Benjamins.

Davidson, Brad. 2000. "The Interpreter as Institutional Gatekeeper: The SocialLinguistic role of Interpreters in Spanish-English Medical Discourse". Journal of Sociolinguistics 4(3): 379-405.

Curcó, Carmen. 1998. “¿No me harías un favorcito? Reflexiones en torno a la expresión de la cortesía verbal en el español de México y en el español peninsular". Diálogos Hispánicos de Amsterdam 22: 129-171.

Félix-Brasdefer, J. César. 2006. "Linguistic Politeness in Mexico: Refusal Strategies among Male Speakers of Mexican Spanish". Journal of Pragmatics 38: 21582187.

Filipović, Luna. 2007. "Language as a Witness: Insights from Cognitive Linguistics". International Journal of Speech, Language and the Law 14(2): 245-267.

Filipović, Luna. 2011. "Speaking and Remembering in One or Two Languages: Bilingual vs. Monolingual Lexicalisation and Memory for Motion Events". International Journal of Bilingualism 15(4): 466-485. 
Filipović, Luna. 2013. "Constructing Causation in Language and Memory: Implications for Access to Justice in Multilingual Interactions". International Journal of Speech, Language and the Law 20(1): 1-19.

Filipović, Luna. 2016. "May vs. Might in Native vs. Non-native English: Implications for Inference and Judgement in Legal and Educational Contexts". Applied Linguistics Review 7(2): 181-201.

Filipović, Luna. 2017a. “Applied Language Typology: Applying Typological Insights in Practice". Languages in Contrast 17(2): 255-278.

Filipović, Luna. 2017b. "Applying Language Typology: Practical Applications of Research on Typological Contrasts between Languages". In Motion and Space across Languages. Theory and Applications, ed. by Iraide Ibarretxe-Antuñano, 399-418. Amsterdam: John Benjamins.

Filipović, Luna, and Alberto Hijazo-Gascón. 2018. "Interpreting Meaning in Police Interviews: Applied Language Typology in a Forensic Linguistics Context". Vigo International Journal of Applied Linguistics VIAL 15: 67-103.

Gile, D. 1997. "Conference Interpreting as a Cognitive Management Problem". In Cognitive Processes in Translation and Interpreting, ed. by Joseph H. Danks, Gregory M. Shreve, Stephen B. Fountain and Michael McBeath, 96-214. London: Sage.

Hale, Sandra Beatriz. 2007. Community Interpreting. Hampshire: Palgrave Macmillan. Huang, Yan. 2007. Pragmatics. Oxford: Oxford University Press.

Ibarretxe-Antuñano, Iraide. 2012. "Placement and Removal Events in Basque and Spanish". In The events of putting and taking. A crosslinguistic perspective, ed. by Anetta Kopecka and Bhuvana Narasinhan, 123-143. Amsterdam: John Benjamins.

Ibarretxe-Antuñano, Iraide, and Luna Filipović. 2013. "Lexicalisation patterns and Translation". In Cognitive Linguistics and Translation, ed. by Ana Rojo and Iraide Ibarretxe-Antuñano, 253-284. Berlin: Mouton de Gruyter.

Jacobsen, Bente. 2002. Pragmatic Meaning in Court Interpreting: An Empirical Study in Consecutively Interpreted Question-Answer Dialoguers. Unpublished $\mathrm{PhD}$ Thesis. The Aarhus School of Business.

Krouglov, Alexander. 1999. "Police Interpreting: Politeness and Sociocultural Context". The Translator 5(2): 285-302.

López Morales, Humberto. 2005. "Sociolingüística del tabú". Interlingüística 16(1): 720.

Rojo, Ana, and Paula Cifuentes-Férez. 2017. "On the Reception of Translations: Exploring the Impact of Typological Differences on Legal Contexts". In Motion and Space across Languages. Theory and Applications, ed. by Iraide IbarretxeAntuñano, 367-398. Amsterdam: John Benjamins.

Russell, Debra. 2002. Interpreting in Legal Contexts: Consecutive and Simultaneous Interpretation. Burtonsville, Md.: Linstok Press.

Slobin, Dan I. 1991. "Learning to Think for Speaking. Native Language, Cognition and Rhetorical Style". Pragmatics 1: 7-29.

Slobin, Dan I. 1996a. "From 'thought and language' to 'thinking for speaking"”. In Rethinking linguistic relativity, ed. by John J. Gumperz and Stephen C. Levinson, 70-96. Cambridge: Cambridge University Press.

Slobin, Dan I. 1996b. "Two Ways to Travel: Verbs of Motion in English and Spanish". In Grammatical constructions. Their form and meaning, ed. by Masayoshi Shibatani and Sandra A. Thompson, 195-220. Oxford: Clarendon Press. 
Slobin, Dan I. 1997. "Mind, Code and Text". In Essays on language functions and language type. Dedicated to T. Givón, ed. by Joan Bybee, John Haiman, and Sandra A. Thompson, 437-467. Amsterdam: John Benjamins.

Slobin, Dan I., and Nini Hoiting. 1994. "Reference to Movement in Spoken and Signed Languages: Typological Considerations". Proceedings of the Twentieth Annual Meeting of the Berkeley Linguistics Society 20: 487-503.

Song, Jae Jung. 2010. The Oxford Handbook of Linguistic Typology. Oxford: Oxford University Press.

Talmy, Leonard. 1988. "Force Dynamics in Language and Cognition". Cognitive Science 12: 49-100.

Talmy, Leonard. 1991. "Path to Realisation: A Typology of Event Conflation". Proceedings of the Seventeenth Annual Meeting of the Berkeley Linguistics Society 17: 480-519.

Talmy, Leonard. 2000. Toward a cognitive semantics. Cambridge, Mass.: MIT Press.

Vermeer, Hans J. 1998. "Starting to Unmask what Translatology is about", Target 10(1): 41-68.

\section{Address for correspondence}

Alberto Hijazo-Gascón

School of Politics, Philosophy, Language and Communication Studies

University of East Anglia

Norwich Research Park

Norwich NR4 7TJ

UK

A.Hijazo-Gascon@uea.ac.uk

\section{Biographical note}

Alberto Hijazo-Gascón is Senior Lecturer of Intercultural Communication and Spanish at the University of East Anglia in Norwich. His research interests focus on Cognitive and Applied Linguistics, especially in relation to Second Language Acquisition and Forensic Linguistics. He has published on language transfer, typology and metaphor in relation to multilingualism and language acquisition. 